\title{
¿Quién subvierte el Concilio? Respuesta al Cardenal J. Ratzinger a propósito de la Dominus lesus*
}

\author{
Leonardo Boff, \\ Universidad del Estado de Rio de Janeiro.
}

¿En qué sentido debe ser entendida la afirmación de la Lumen Gentium de que "la Iglesia de Cristo, constituida y organizada en este mundo como una sociedad, subsiste (subsistit in) en la Iglesia Católica gobemada por el sucesor de Pedro y por los obispos en comunión con él, aunque fuera de su estructura visible se encuentren varios elementos de santificación y verdad" (n. 8)?

\section{La controversia acerca del subsistit in}

En mi libro Iglesia: carisma y poder (1981) decía "La Iglesia calólica, apostólica, romana es, por un lado, la Iglesia de Cristo, y, por otro, no lo es. Es

- El Cardenal J. Ratzinger reafirmó tres veces la condenación de mi leclura đel subsistit in del Vaticano II, de la forma más pública, solemne y contundente posible. Me ha honrado ahora con una nota (n. 56) cn su declaración Dominus lesus. Eminentes tcólogos de varias partes del mundo, incluso allas autoridades eclesiáslicas, me han solicitado que dé una respuesta. Contra mi gusto lo hago, pues, en una perspecliva global, considero cstas cuestiones como intra-sistémicas c irrclevantes para la mayoría de la humanidad y de los propios cristianos quc sc guían por cl cvangclio.

Publiqué primero una versión profético-denunciatoria bajo cl título: "Ratzinger: exterminador do futuro?", publicada en el Jornal do Brasil los días 4, 5 y 6 de oclubre de 2000 y en la Revista Electrónica Latinnamericana de Teología (http:// servicioskoinonia. Org/rclat), y ahora ésla, de tenor cslrictamentc histórico-tcológico. Vivo en la periferia del mundo y de la Iglesia, con recursos bibliográficos reducidos. Aun así, he asumido esta tarea con la seriedad necesaria y posible a mis limilaciones. Pero no pretendo volver más sobrc clla. 
Iglesia de Cristo porque en esta mediación concreta ella aparece en el mundo. Pero no lo es, porque no se puede pretender identificarla exclusivamente con la Iglesia de Cristo, ya que ésta puede subsistir también en otras iglesias cristianas. El Concilio Vaticano II, superando una ambigüedad teológica de eclesiologías anteriores que tendían a identificar pura y simplemente la Iglesia de Cristo con la lglesia católica romana, enseña con acierto: 'Esta Iglesia (de Cristo) subsiste en la Iglesia católica' (subsistit in: tiene su forma concreta en la Iglesia calólica). Evila decir, como se dice en documentos anteriores, es la Iglesia de Cristo" (p. 134).

En la nolificación de la Sagrada Congregación para la Doclrina de la Fe (1985), que censuraba el libro (e imponía un año de "silencio obsequioso" a su aulor), su prefecto, el Cardenal J. Ralzinger, se muestra especialmente duro contra esta interpretación. Afirma que Boff "extrae una tesis exaclamente contraria a la significación auténtica del texto conciliar. El Concilio había escogido, sin embargo, la palabra subsistit exactamente para esclarecer que hay una única "subsistencia" de la Iglesia verdadera, mientras que fuera de su estructura visible existen solamente "elementos de Iglesia", que — por ser elementos de la misma Iglesiatienden y conducen en dirección a la lglesia católica (Lumen Gentium, 8)". Y el texto de la notificación, concluye: "la subversión del significado del texto conciliar sobre la subsistencia de la Iglesia está en la base del relativismo eclesiológico de $\mathbf{L}$. Boff... en el cual se desarrolla y se explicita un profundo desentendimiento de aquello que la fe calólica profesa respecto a la Iglesia de Dios en el mundo" (cfr. AAS 77,1985, pp. 756-762).

En el Congreso Internacional sobre la actuación del Vaticano II (Roma, 2527 de febrero de 2000) revelaba el mismo Cardenal J. Ratzinger, en su discurso doctrinal sobre "la naturaleza de la Iglesia", en el cual retoma la cuestión del subsistis in, que esa postura contra el libro de L. Boff "es el único pronunciamiento oficial del magisterio después del Concilio, sobre esta palabra, y que no puede ser desatendido" ( $c f r$. el texto en // Regno, 7,2000, p. 237a).

En esa misma conferencia, el Cardenal J. Ratzinger enfaliza que "En la diferencia entre subsistit y est se esconde todo el problema ecuménico. La palabra subsistit deriva de la antigua filosofía posteriomente desamollada en la escolástica. A ella corresponde la palabra griega hypostasis, que en la cristología descmpeña una función central, para describir la unión de la naturaleza divina y humana en la persona de Cristo. Subsistere es un caso especial de esse. Es el ser en la forma de un sujeto a se stante (que se sustenta a sí mismo). Aquí se trala exaclamente de eso. El Concilio quiso decirnos que la Iglesia de Jesucristo como sujeto concreto en este mundo puede ser encontrada en la Iglesia católica. Y eso sólo puede ocurrir una única vez y la concepción según la cual el subsistit podría multiplicarse no capla propiamente lo que se pretendía decir. Con la palabra subsistit el Concilio quería expresar la singularidad y no la multiplicidad de la Iglesia católica; existe la Iglesia como sujeto en la realidad histórica" (cfr. // Regno, p. 237b). 
Esta interpretación personal del Cardenal J. Ratzinger es Iraladada a la declaración Dominus lesus (6 de agosto de 2000) de la Sagrada Congregación para la Doctrina de la $\mathrm{Fe}$, de la cual es prefecto: "Con la expresión subsistil in, el concilio Vaticano II quiso armonizar dos afirmaciones doctrinales: por un lado, la de que la lglesia de Cristo, no obstante las divisiones de los cristianos, continúa existiendo plenamente sólo en la Iglesia Católica y, por otro, la de que 'existen numerosos elementos de santificación y de verdad fuera de su composición', o sea, en las iglesias y comunidades eclesiales que todavía no viven en plena comunión con la lglesia católica" (n. 16). En nota a pie de página (n. 56), la declaración, honrándome, cita explícitamente la nolificación contra $\mathrm{L}$. Boff y reitera que la intención del concilio fue la de reafirmar con la expresión subsistit in la "única subsistencia" de la Iglesia católica.

\section{2. ¿Cuál fue la mens Patrum Concilii sobre el subsistit in}

He ahí, pues, los términos de la controvesia. Cabe ahora preguntar: esa interpretación del Cardenal J. Ratzinger, ¿corresponde de hecho a la verdad histórica del concilio, o es la recepción que él hace, por su cuenta, dentro de un cierto tipo de comprensión de la naturaleza de la Iglesia, que él personalmente tiene? Aquí importa sacar a la luz la verdad histórica, expresada por un concilio ecuménico, cuya autoridad está por encima de la Sagrada Congregación de la Doctrina de la Fe y de su eventual prefecto. Este, en la persona del Cardenal J. Ratzinger, debe atenerse a la mens Parrum Concilii (la mente de los padres del Concilio), como cualquier otro fiel o teólogo. ¿Cuál es, de hecho, esá mens Patrum?

Para responder a esa cuestión necesitamos tener siempre en mente no sólo el término subsistit in, sino tres elementos fundamentales. Primero, los textos preparatorios, previos a la Lumen Gentium, considerando cómo ellos plantearon la relación de la Iglesia de Cristo con la Iglesia católica (en ellos se da la expresión est). Segundo, cuál es el senlido del № 8 de la Lumen Gentium, donde aparece la expresión subsistit in (sustituyendo al est). Tercero, importa tomar en serio lo que el Papa Pablo VI enfatizó en el momento mismo en que se sancionaba la Lumen Gentium (Constitución dogmática sobre la Iglesia) junto con la Unitatis Redintegratio (sobre el ecumenismo), a saber. que la doctrina conciliar sobre la Iglesia debe ser interpretada a la luz de las explicaciones del decreto sobre el ecumenismo (AAS 56, 1964, pp. 1012-1013). Y -añadiriamos- también a la luz de los pronunciamientos del magisterio pontificio, sinodal y episcopal del pos-concilio, cuando se refieren a olras iglesias no calólicas.

\subsection{Subsistit in no es sinónimo de est ,}

Los comentaristas de la Lumen Gentium registraron la cvolución que se dio en los varios esquemas De Ecclesia, propuestos a los padres conciliares en liss 
discusiones, en el aula, que antecedieron a la aprobación final de la Lumen Gentium (21 de noviembre de 1964, junto con el decreto sobre el ecumenismo Unitatis Redintegratio). En el esquema de 1962 se decía, en consonancia con el consenso de la teología y de la enseñanza del magisterio de aquel tiempo: "La Iglesia católica romana es (est) el Cuerpo de Cristo... y solamente aquella que es católica romana liene el derecho de ser llamada Iglesia" (Acta Synodalia Vaticani $[1,1 / 4$, p. 15). Varios padres conciliares hicieron críticas a esta identificación pura y simple (como los significativos cardenales Bea y Lienard), en razón de su resonancia antiecuménica.

El esquema De Ecclesia de 1963 continuaba afirmando la identificación, pero introdujo una apertura, al reconocer que "muchos (plura) elementos de santificación pueden encontrarse luera de su entera estruclura (de Iglesia)". "Son elementos que pertenecen propiamente (in proprio) a la Iglesia de Cristo" (Acta Synodalia, op. cit. II/1, pp. 219-220). Aquí se constata, ineludiblemente, un progreso, pues se reconoce la existencia de elementos eclesiales más allá de los límites de la Iglesia católica.

El esquema definitivo de 1964 asumió los añadidos y trató de conciliar las dos afirmaciones: por un lado, la identificación de la lglesia de Cristo con la Iglesia católica, y por otro, la admisión de la existencia de elementos eclesiales fuera de ella. La fórmula encontrada fue sustituir el est por el subsistit in. El texto final, por lo tanto, no afirma ya que la Iglesia de Cristo "es" la Iglesia católica, sino que dice: la Iglesia de Cristo "subsiste en la Iglesia católica". ¿Cuál es el sentido exacto de este cambio?

La comisión teológica del Concilio da las razones del cambio: "para que la expresión concuerde mejor con la afirmación acerca de elementos eclesiales (de elementis ecclesiasticibus) que se encuentran más altá" (alibi, en el sentido de "más allá de la Iglesia católica": Acta Synodalia, op. cit. p. 177). Pero la comisión nunca explicó oficialmente qué se entiende por subsistit in. Apuntó, sin embargo, en una dirección segura: al resumir el № 8 de la Lumen Gentium, en el cual aparece la expresión subsistit in, hace dos afirmaciones que ayudan a entender el subsistit in: "La intención del $N^{0} 8$ es mostrar que la Iglesia, cuya naturaleza íntima y secreta se describe, naturaleza por la cual se une perpetuamente con Cristo y su obra, es enconlrada concretamente (concrete inveniri) en esta tierra, en la Iglesia calólica. Esta Iglesia empírica (haec autem Ecclesia empirica) revela un misterio, aunque no sin sombras, y por eso debe ser llevada a plena luz, así como también Cristo, el Señor, por la humillación llegó a la gloria. De esta forma se previene contra la impresión de que la descripción propuesta por el Concilio sea meramente idealística e irreal" (Acta Synodalia III/1, p. 176). La expresión "es encontrada concretamente" nos ayuda a enlender el subsistit in también en términos concretos y no abstractos. Eso queda más claro en la segunda afimación, cuando dice: "La Iglesia es única y en esta tierra 
está presente (adest in) en la Iglesia católica, aunque fuera de ella se encuentren elementos eclesiales" (Acıa Synodalia II/I, p. 176). Adest in (está presente) corresponde claramente a subsistit in (subsiste).

Esas indicaciones son fundamentales, pues cierran la puerta a una interpretación puramente sustancialista e identificadora de la Iglesia de Cristo con la Iglesia católica, invalidando así un avance sobre la eclesiología preconciliar.

Pero importa profundizar en la expresión subsistit in. Cuando no hay una interpretación específica y oficial de una palabra, como es el caso de subsistit in, debemos seguir la regla general de la hermenéutica: las palabras tienen el sentido que les confiere su uso común.

¿Cuál es el sentido común de subsistere? Sírvanos de referencia el clásico diccionario lalino de Forcellini. Los muchos senlidos que presenta van, sin excepción, en la línea de lo concreto y de lo histórico (como sugiere la explicación de la comisión teológica del Concilio acercá del $N^{9} 8$ de la Lumen Gentium). Los sinónimos de subsistere son: "manere, permanere, sustentare, resistere, consistere, fermare, adstare" (Totius Latinitatis Lexicon, Vol. V, pp. 707-708). Ninguno en la línea que pretende el Cardenal J. Ratzinger de la hypóstasis y de la subsistencia como término técnico de la cristología. Observando los ejemplos dados por Forcellini, se comprueba claramente que el subsistif in permite ser traducido por "hacerse presente, ser encontrado concretamente, ganar forma y concretizarse".

Resumiento: el est remite a una visión esencialista, substancialista y de identificación, y pide una definición esencial de la Iglesia. El subsisti in apunta hacia una visión concreta y empírica, en el sentido concreto del № 8 de la Lumen Gentium. Y ese sentido es que la Iglesia de Cristo "subsiste en la" Iglesia católica, es decir, gana forma concreta y se concretiza en la lglesia católica.

A base de esta comprensión, se entiende que los padres conciliares hayan sustituido el est ("est", expresión de la sustancia y de la identificación) por subsistit in (gana forma concreta, se concretiza). La Iglesia de Cristo se concretiza en la Iglesia católica, apostólica, romana. Pero no se agota en esa concretización, pues ella, a causa de las limitaciones históricas, culturales-occidentales y otras, especialmente en razón de las sombras y de los pecadores presentes en su interior (Lumen Gentium, 8), no puede identificarse in toto, pure et simpliciter (su totalidad, pura y simplemente), sin diferencia, con la Iglesia de Cristo. La Iglesia es semper reformanda y en la tradición de los padres aparece como la casta meretriz, y, por eso, como una realidad del tempus medium con las marcas limitantes de la peregrinación, rumbo a la plenilud, posible sólo en la escalología.

Iglesia de Cristo e Iglesia católica no se cubren totalmente. La Iglesia de Cristo es mayor que la Iglesia católica. Por eso, la Iglesia de Cristo puede subsistir, es decir, puede ganar otras expresiones histórico culturales, a lo largo de la 
historia de la misma Iglesia católica ayer y hoy, en otras iglesias cristianas y comunidades eclesiales. Juntas y en comunión entre sí, forman la Iglesia de Cristo, en la historia, la Iglesia de Dios, a través de los tiempos.

De toda esta argumentación queda claro: subsistit in no es sinónimo de est. Si fuese sinónimo, ¿por qué entonces el cambio introducido por los padres conciliares? En otras palabras, la decisión de no usar ya el "es" apunta a evilar una identificación pura y simple de la Iglesia de Cristo con la Iglesia católica. Al hacer esto, los padres conciliares abren un espacio para que "los muchos elementos de santificación y de verdad" sean un espacio para que "los muchos elementos de santificación y de verdad" sean reconocidos como "eclesiales". Por lo tanto, la Iglesia de Cristo desborda a la Iglesia católica.

\subsection{El retroceso del Cardenal J. Ratzinger al pre-Vaticano II}

La interpretación del Cardenal Ratzinger hace del subsistit in un equivalente de est ("un caso especial de esse", como dijo explícitamente, en su conferencia sobre la naturaleza de la Iglesia: / Regno, op. cit., p. 237b). Por eso podia decir, como lo hizo en la Notificación (1985) contra mi libro Iglesia: carisma y poder: "existe una única 'subsistencia' de la verdadera Iglesia, mientras que fuera de su estructura visible existen solamente elementa Ecclesiae, que -siendo elementos de la misma Iglesia - tienden y conducen a la Iglesia católica" (AAS 71, 1985, pp. 758-759). Lo mismo ha repetido en la Dominus lesus (No 16, citándome explícitamente en la nota 56 ).

Aquí hay un evidente retroceso a la posición anlerior al Vaticano II, superada por la Lumen Gentium. La identificación hecha por el Cardenal J. Ratzinger, entre Iglesia de Cristo e Iglesia calólica es lan exclusiva que fuera de ella no hay Iglesia, solamente "elementos de Iglesia".

Notemos una modificación importante: el texio del Cardenal J. Ratzinger afirma que fuera de la Iglesia católica existen solamente elementos eclesiales, mientras que el concilio no habla así. Dice positivamente que existen "muchos elementos" (plura) y no "solamente" (solum) elementos de Iglesia.

Más lodavía, la Lumen Gentium, en el N" 15, al referirse a los muchos modos como la Iglesia católica está unida con los cristianos no católicos, enseña que esos cristianos reciben el baulismo y "hasta reconocen y aceptan olros sacramentos en las propias iglesias o comunidades eclesiáslicas" (in propiis Ecclesiis vel Communitatibus ecclesiasticis). El informe de la comisión teológica aclara que tales sacramentos son recibidos en sus iglesias o cumnidades cristianas en cuanto tales (cfr. Acta Synodalia, IIJ/7, p. 36: in quanto tali ipsae Ecclesiae vel Communitates). Por lo tanto, no se trata sólo de "elementos de Iglesia", que conciernen sólo a los individuos, sino lambién a sus comunidades. El informe de la comisión leológica subraya con claridad: "preci- 
samente en el renocimiento de este hecho se sitúa el fundamento del movimiento ecuménico" (Acta Synodalia, III/1, p. 204). En razón de eso, podia el decrelo sobre el ecumenismo decir que esas iglesias separadas y comunidades eclesiales "no están de ninguna manera desprovistas de significado y de peso en el mistcrio de la salvación, porque el Espíritu no rehúsa servirse de ellas como instrumentos de salvación" ( $\mathrm{N}^{2} 3 d$ ). Por lo tanto, no sólo los sacramentos poseen valor salvífico, sino también las iglesias y comunidades eclesiales en cuanto tales, como por lo demás vuelve a reafirmar la comisión teológica (cfr. Acta Synodalia, III/7, p. 36: "el Espíritu Santo se sirve de aquellas comunidades como instrumentos de salvación").

Además, la expresión "comunidades eclesiales" aplicada a las "iglesias" surgidas de la reforma, revela que ellas poseen un carácler eclesial, es decir, un carácter de Iglesia, aunque no se les atribuya oficialmente tal tílulo. El informe de la comisión teológica, haciendo referencia a la praxis común de hablar de ellas en términos de comunidades eclesiales, explica que tales comunidades no son una suma de individuos, sino que "están constiluidas por elementos sociales y eclesiásticos... que les confieren un carácter verdaderamente eclesial. En tales comunidades, aunque de un modo imperfecto, está presente la única Iglesia de Cristo, de una manera semejante a aquella según la cual está presente en las iglesias particulares, y por medio de sus elementos eclesiales la Iglesia de Cristo es, de algún modo, operante en ellas" (Acia Synodalia, III, 2, p. 335).

Aquí se dice con todas las letras que la Iglesia de Cristo está presente (el sentido de adest in y subsistif in) en las comunidades eclesiales, aunque imperfectamente. Así como está presente en las iglesias particulares, como la ortodoxa y la de los viejos católicos, está de forma semejante presente en las comunidades eclesiales. Por lo tanto, no se puede negar a tales comunidades el carácter de Iglesia, aunque en el lenguaje acostumbrado del magisterio no sean denominadas técnicamente como iglesias. Por lo demás, el mismo magisterio papal, sinodal y episcopal, posterior al conciclio Vaticano II, aplica el término Iglesia a las comunidades eclesiales no católicas. No se trata, seguramente, de mera concesión a la gentileza del lenguaje. Se trata, sí, de una clarificación y expansión orgánica de un sentido teológico verdadero, subyacente en la fórmula "elementos eclesiales". Este sentido es como una simiente lanzada en tierra fértil por el Vaticano II. Esa simiente se transformó posteriormente en flor y en fruto. La conciencia teológica creció hasta el punto de que se puede afirmar que todas las iglesias y comunidades eclesiales participan de la Iglesia de Cristo.

Como ejemplo aduzcamos el lexto común del obispo católico alemán Monseñor Tenhumberg y del Paeses evangélico en el libro Die Kirche auf gemeinsamen Wege: el ser-Iglesia no coincide simplemente con la Iglesia calólica. Hay también fuera de la Iglesia católica innumerables elementos eclesiales. Los textos conciliares, por eso, aplican los conceptos "iglesias y comunidades 
eclesiales" también a otras comunidades crislianas. Ellas participan de la Iglesia fundada por Cristo. Hay varios grados de densidad en la concretización de la Iglesia como instilución fundada por Cristo" (p. 256).

¿Cómo expresar teológicamente esos varios grados de densidad en la concretización de la Iglesia? El Concilio mismo nos da la fórmula: entender la Iglesia como sacramentum. Es lo que defendíamos en nuesira tesis doctoral Die Kirche als Sakrament im Horizont der Welterfahrung (Paderbom, 1972) y en nuestro libro censurado Iglesia: carisma y poder (198I). Inlentamos mostrar la fecundidad de la categoría sacramentum (señal e instrumento) para señalar los distintos grados de densidad y de concrelización en la manifestación de una misma realidad (sacramentum, res et sacramentum, res). Como sabemos, se trata de un término que viene de la más antigua tradición común de la Iglesia, usado ya en el siglo segundo para definir la naluraleza de la Iglesia como sacramentum Christi.

\subsection{Las contradicciones del Cardenal J. Ratzinger}

Tal interpretación invalida la comprensión del Cardenal J. Ratzinger que fuerza la expresión subsistit in y la traduce por "subsistencia", en el sentido abstracto teológico-filosófico, cuando su contexto es concreto y empírico. Es como si alguien dijese a otro: "casa, en realidad, sólo es la mía; la tuya no es casa; tú sólo tienes elementos de casa (elementa Ecclesiae), como ladrillos, ventanas, tejas, mesas y armarios, elementos de casa que fueron sustraídos de la mía y que, por eso, están clamando por su dueño. y deben por tanto volver a mi casa".

Tal afirmación, además de arrogante, es errónea, según la mens Patrum que acabamos de sacar a la luz. El mismo Cardenal J. Ratzinger se da cuenta de los problemas insolubles de su interpretación. En su conferencia sobre la naluraleza de la Iglesia, dice a este respecto: "esta diferencia entre subsistit y est no se puede resolver plenamenle, en úllimo término desde el punlo de vista lógico" (cfr. Il Regno, op. cit. p. 237b). ¿Qué es lo que está alirmando? Confiesa simplemente un impase. Con seguridad, el Concilio con el subsistit in no quiso introdùcir impases, ni nuevos problemas; al contrario, quiso resolver problemas. El problema no está en el Concilio, sino en la cabeza del Cardenal J. Ratzinger con su interpretación reduccionista. Ese reduccionismo se revela al final de su explicación sobre la naturaleza de la Iglesia. Al reconocer el desastre que significa el pecado de la desunión de las iglesias, afirma, paradójicamente: "En la medida en que la división como realidad histórica es perceptible en cada uno, la subsistencia de la única lglesia en la figura concreta de la Iglesia católica sólo puede ser percibida como tal en la fe" (II Regno, op. cit., p. 238a).

La posición del Cardenal J. Ratzinger se agrava, pues hace que se evaporen sus propios argumentos sobre la concreción hislórica de la Iglesia de Cristo. Más todavía, compromete la lectura del número 8 de la Lumen Gentium, que da 
énfasis a la Iglesia empírica, concreta, estructurada. Por lo tanlo, en algo que se ve, que se toca, que se capta por los sentidos corporales. Ahora comparece el Cardenal J. Ratzinger y afirma la contrario, que la percepción es de fe, por lo tanto, por los sentidos no corporales. La unidad se invisibiliza y se desrealiza, destruyendo toda la argumentación del concilio. Tal es la consecuencia de la interpretación del Cardenal J. Ratzinger, fatalmente contraria a la mens Patrum y al concilio mismo. Hubiera sido más sencillo si el Cardenal J. Ratzinger, en obediencia a esa mens Patrum, afirmase humilde y verdaderamente: la Iglesia de Cristo se realiza concretamente en las iglesias y comunidades cristianas, en diversos grados de visibilidad y de plenitud, por ejemplo, en las pequeñas comunidades eclesiales de base de las favelas de Rio de Janeiro y en el interior de la floresta amazónica (y jcómo se alegran esas comunidades al sentir y saber que son realmente Iglesia de Cristo, incluso sin tener eucaristía ni sacerdocio!), en otras iglesias cristianas y comunidades eclesiales, que se refieren a Cristo como salvador, libertador y Verbo encarnado.

Hasta podríamos concederle la prelensión de que la lglesia católica que él tanto exalta y ardorosamente defiende contenga la plena visibilidad y plenitud (la cual ha de ser siempre comprobada por los hechos y no sólo fundamentalistamente afimada). Pero eso no impide que esia misma Iglesia de Cristo esté presente en otras iglesias cristianas, en tantos puntos, hasta con más visibilidad y densidad que en la lglesia católica, como, por ejemplo, en el amor a las Escrituras sagradas de nuestros hermanos y hermanas evangélicos o en el cultivo de la liturgia solemne de nuestros hermanos y hermanas ortodoxos.

\subsection{Peligros de la interpretación del Cardenal J. Ratzinger}

La concentración de la Iglesia católica no puede ser tanta que agote y extenúe en sí misma las virtualidades de la Iglesia de Cristo. Sería tan ridículo y peligroso como si alguien dijese: la naturaleza humana está tan presente en la raza negra, por ser profundamente espiritual, estética y solidaria, que sólo ella es humana. La raza blanca occidental, europea y bávara, por el imperialismo, el colonialismo y las guerras de exterminio que produjo, no seria humana, simplemente contendría "elementos de humanidad". Lógicamente, es humana, tal vez demasiado humana.

Pero tal afirmación exclusivista, semejante a aquella del Cardenal J. Ratzinger, es extremadamente peligrosa. Ella fue esgrimida concretamente por los cristianos europeos en confrontación con los indígenas "descubiertos" en América y el Caribe. En la famosa "Controversia de Valladolid" (1550-1551), entre Bartolomé de las Casas, defensor de los indios, y Juan Ginés de Sepúlveda, humanista y preceplor de la familia real española. Este último llegó a afirmar: los indígenas no son hijos de Adán como nosolros, sino animales tan expertos que, para engañamos, hablan y hasta construyen casas y ciudades semejantes a las nuestras. 
No siendo de nuestra familia humana, pueden —esa era la conclusión- ser tratados como animales y ser esclavizados tranquilamente. Sabemos que el Papa Paulo III ya antes habia intervenido liberadoramente con la bula Sublimis Deus (1537) y había reafirmado que los indígenas son hijos de Adán, hermanos y hermanas nuestros, tienen derecho a sus tierras y no deben ser maltratados. El cardenal legado reasumió la afirmación de Paulo III y dio la razón a Bartolomé de las Casas contra Sepúlveda.

Una lógica semejante a la de Juan Ginés de Sepúlveda es la que fundamenta la argumentación del Cardenal J. Ratzinger. Lo que el conocido inteleclual y cientílico francés Miche Serres dice de la Declaración Universal de los Derechos Humanos puede ser dicho de la eclesiología reduccionisla del Cardenal J. Ratzinger. Dice M. Serres: la Declaración Universal de los Derechos Humanos tuvo el mérito de afirmar que "todos los hombres tienen derechos", mas tuvo el defecto de entender "sólo los hombres tiene derechos". Fue preciso mucha lucha para extender esos derechos a las mujeres, a los negros, a los indígenas y, aclualmente, a la tierra como Magna Mater, a los ecosistemas y a cada ser de la creación. El Cardenal J. Ratzinger luvo el mérito de decir: "la Iglesia de Cristo subsiste en la Iglesia calólica". Mas tuvo el defecto de entender: "sólo en la Iglesia católica". Ahora entendemos que no es sólo un defecto, sino un error, contrario a la mente de los padres del Vaticano II.

Así como todos hemos crecido en la comprensión de los derechos extendidos a toda la creación, así, el Cardenal J. Ratzinger y sus seguidores tendrán que aprender, según las orientaciones del Vaticano II, a extender la eclesialidad de la Iglesia de Cristo a todas las iglesias y comunidades eclesiales. Entonces sí, el ecumenismo será fecundo y la emulación, generosa, en el sentido de ver cuál de las iglesias vive mejor y anuncia más adecuadamente el evangelio de Jesús, un sueño posible a la entera humanidad, y quién lo expresa de forma más visible, más concreta y más convincente dentro de este nuestro mundo, que se está globalizando.

Concluyendo esta parte, volvemos a subrayar: la distinción entre el est y el subsistit in hecha por los padres conciliares abrió un camino nuevo para el ecumenismo católico, que no podrá ya ser clausurado. El Cardenal J. Ratzinger, en la Dominus lesus, erróneamente usa el subsistit in para cerrar el ecumenismo católico abierto, reafimar la identificación exclusiva de la Iglesia católica romana con la Iglesia de Crislo, y hacer así volver a aquello que el Concilio quiso superar: al est, a la identificación pura y simple, sin distinción.

En razón de estas reflexiones, cabría devolver la pregunta: ¿quién está haciendo "la subversión del texto conciliar sobre la subsistencia de la Iglesia"? ¿El libro Iglesia: carisma y poder, o la Notificación del Cardenal Ratzinger contra él, reafirmada en la declaración Dominus lesus? 


\section{Caminos para el ecumenismo católico}

Dejando la polémica, importa ahora sugerir algunos punlos, derivados del Vaticano II mismo, que puedan fundamentar un ecumenismo católico menos arrogante y más dialogal. Antes, sin embargo, cabe hacer algunas consideraciones de orgen teológico-pastoral.

Se dice, y la Domimus lesus lo subraya fucrtemente, que la Iglesia es enviada a anunciar el evangelio al mundo, según el mandato del Señor. Sin embargo, observando la producción de la Sagrada Congregación para la Doctrina de la Fe, en esta última declaración y en tantas otras, se nota una ausencia clamorosa de conocimiento del mundo actual, con sus oportunidades y sus riesgos. $Y$ cuando se ofrece alguna perspectiva, es casi siempre pesimista, típica de instituciones en crisis de fe y de esperanza. Todo está fundamentalmente vuelto hacia adentro, construyendo la Iglesia como un bastión que se preserva y se basta a si mismo. Con esa actitud solipsista no se evangeliza y no se va ad gentes.

O las iglesias - sobre todo la católica- se abren a la nueva fase de la humanidad, la planetaria, o se condenan a ser un subproducto de la cultura occidental. Aquí debemos asumir como virtud lo que el Cardenal J. Ratzinger considera vicio a ser duramente combatido: el relativismo eclesiológico.

Debemos ser doblemente relativistas. Primeramente, debemos relativizar la expresión occidental de la Iglesia de Cristo, romana más específicamente. En su teoría del poder y en la forma como lo organiza y lo distribuye, se nota la mentalidad romana, centralizadora y autoritaria, muy diversa de la evangélica. Si el cristianismo se hubiese encarnado, por ejemplo, en la gran cultura lupiguaraní, cultura común de millones de indigenas, otro habría sido el sentido del poder. Para este pueblo, el cacique se caracteriza por la generosidad, por el servicio incondicional a los otros y por la donación de todo lo que posee. En algunas tribus se puede reconocer el jefe en la persona de aquel que posee menos que los otros y que lleva omamentos más pobres y hasta miserables, pues todo lo donó. Si el cristianismo, en vez de haberse encamado en la cultura romana con su legalismo y con su centralización, se hubiese encamado en la cultura política tupí-guaraní, tendríamos entonces sacerdotes pobres, obispos miserables y el papa... un verdadero mendigo. Entonces sí, podrían ser testigos de Aquel que dijo: "estoy entre ustedes como quien sirve, y quien quiera ser el primero que sea el último". Y la misión no habría sido dominación religiosa, aliada a la dominación política; los cristianos no serían cómplices y participes del genocidio de los pueblos originarios de América Latina y de otras partes. Tendríamos, seguramente, una lglesia mejor, más sensible, más participativa, más servicial, más integrada, más ecológica y más espiritual que la romano católica.

La catolicidad del cristianismo y de todas las iglesias pasa por la capacidad de relativización de su encarnación occidental y de apertura a nuevas posibilidades de encarnación, posibles evangélicamente. Pasa también por la capacidad de 
mantener la comunión con todas las encarnaciones, pues todas ellas traducen, bien o mal, el evangelio para el mundo, hoy globalizado.

Liberada de su matriz occidental, la Iglesia católica romana se daria cuenta del ridículo arrogante de las tesis sustentadas por la Dominus lesus. Su lado occidental hace que tenga una visión capilalistica y concentradora de la herencia de Jesús y, al mismo tiempo, una perspectiva imperialista de la misión, como conquista de pueblos y culturas para los cuadros de la eclesialidad romano-occidental.

En segundo lugar, importa relalivizar positivamente la eclesiología, es decir, mantener todas las iglesias y comunidades eclesiales relacionadas unas con otras, pues son expresiones de la misma Iglesia de Cristo. En vez de que una descalifique a la otra, o de disputar si merece o no el atributo de lglesia, debería regirnos la pericóresis entre ellas (inter-retro-relacionamiento de todos con todos), a semejanza de aquella que se da entre las divinas personas de la Santísima Trinidad.

En una perspectiva de globalización, imporla ver el cristianismo más como el movimiento de Jesús en el mundo que como una institución con características pasadas en función de viejas tradiciones, sobrecargada de reflexión y con marcas de los conflictos religioso-políticos que caracterizaron la historia cristiana en occidente.

Hechas estas observaciones, elijamos, sumariamente, algunos puntos doctrinales, inspirados por el Vaticano II, capaces de fundar otro tipo de ecumenismo católico.

En primer lugar, hay que anclar la unidad de la Iglesia en el ministerio trinitario y no en una melafísica clásica y neoescolástica, como hace el Cardenal J. Ralzinger. En el decreto sobre el ecumenismo se dice claramente: "De este misterio [de la unidad de la Iglesia] es modelo supremo y principio la unidad de un Dios en la Trinidad de personas, Padre, Hijo y Espíritu Santo" ( ${ }^{0} 2$ ). En la Trinidad hay diversidad de personas, una no es la otra: no hay ninguna jerarquía entre ellas, pues ninguna persona está encima o debajo de la otra (al contrario que en la Iglesia católica); y, con todo, rige una profunda unidad, que nace de la pericóresis, a saber, del entrelazamiento de todas las divinas personas entre sí, todas acogiéndose en su diversidad y todas autoentregándose totalmente. La esencia de la pericóresis es el amor. Bien decía san Bemardo: "en la Santísima Trinidad, ¿qué es lo que conserva aquella suprema e inefable unidad, sino el amor? El amor constituye la Trinidad en la unidad y, de cierta forma, unifica las personas en el vínculo de la paz. El amor engendra amor. Esta es la ley eterna y universal, ley que crea todo y todo lo gobierna" (Liber de diligendo Deo, c. 12, № 35; PL 192, 996 B). Esa unidad es "modelo supremo" para la unidad de la Iglesia y entre las iglesias. Son diversas, pero todas uni-ficadas en la misma relación de aceptación mulua y de mutuo amor. 
En segundo lugar, la Iglesia ha de ser enlendida como communio, tema importante en el Vaticano II y en toda la eclesiología posconciliar (especialmenle en el Sínodo de 1985), llamada con razón eclesiología de comunión. La primera epístola de san Juan nos ofrece el senlido radicalmente teológico de la comunión: "aquello que vimos y oímos, nosotros se lo anunciamos para que también ustedes estén en comunión con nosotros. Nuestra comunión es con el Padre y con su Hijo Jesucristo" ( $1 J n$ I, 3). Nuevamente, la comunión se realiza en la diversidad de las personas, que se unen por los lazos de vida y amor. Juan Pablo II, delante de todos los obispos latinoamericanos, hizo una declaración de las más bellas de su pontificado: "Nuestro Dios en su misterio más íntimo no es soledad, sino una familia, pues lleva en sí mismo la paternidad, la filiación y la esencia de la familia que es el amor, el Espirilu Santo" (Documentos de Puebla, 28 de enero de 1979, Petrópolis, 1979, 46). Es la comunión entre todas las iglesias la que hace de ella la única Iglesia de Cristo. La Iglesia universal no es otra cosa que la comunión de las iglesias particulares, "en las cuales a partir de las cuales existe (exsistit) la Iglesia católica una única", como dice con pertinencia la Lumen Gentium (N²3a). Familia que expresa aquí la communio. Esta comprensión comunional evita la critica hecha por la declaración Mysterium Ecclesiae, según la cual la Iglesia universal sería el conjunto o la suma (summa) de las iglesias. Por la comunión no se suman las iglesias, sino que se reconoce la comunión real entre ellas, con mayor o menor densidad, pero todas ellas con carácter eclesial.

En tercer lugar, cabe resaltar la importancia de que se enlienda la IglesiaPueblo-de-Dios, considerada por el Cardenal J. Ratzinger en su conferencia sobre la naturaleza de la Iglesia como "lema impropio", "porque se presta menos a describir la estructura jerárquica de la comunidad eclesial" (cfr. I/ Regno, op. cit., pp. 233B-23a). Ahora bien, ahí reside el valor de este concepto de Iglesia. Fue por eso, precisamente, por lo que en la Lumen Gentium fue antepuesto el capítulo sobre la Estruclura jerárquica de la Iglesia (en las fases anteriores, el orden era el contrario).

Este concepto muestra mejor la Iglesia universal como peregrinación y movimiento de todos los que siguen a Jesús, y por lo tanto, de todas las iglesias, antes de que haya dentro de ellas distinciones de ministerios, servicios y carismas. Estos no son facciones, sino funciones de servicio y de animación de toda la comunidad. El conjunto orgánico de todas las iglesias y comunidades eclesiales - conjunto estructurado por relaciones de comunión y servicio al mundo- constituye, fundamentalmente, el Pueblo de Dios en marcha. Eso está bien expresado por el término bíblico y profundamente teológico de "Pueblo de Dios", lógicamente incómodo a las construcciones reduccionistas del Cardenal J. Ratzinger.

En cuarto lugar, es decisiva la misión para que se entienda la naturaleza de la Iglesia de Cristo. Esta no existe para sí. No es a ella a la que Dios ama, en 
primer lugar, sino al mundo, pues a él envió a su Hijo (Jn 3, 16). Frenle al mundo, ella tiene una estructura "sacramental", es señal e instrumento, por tanto, de Cristo para el mundo. Debe apuntar hacia Cristo, y no sustiluirlo. Debe, por un lado, afirmarse, porque mediante ella la herencia de Jesús se mantiene viva en la historia. Pero, por olro, debe simultáneamente negarse para que Cristo aparezca y gane centralidad. La Iglesia posee solamente centralidad en la medida en que está en Cristo y en el Espiritu y no fundada en si misma. Es a partir de la misión como ella entiende que perlencce al orden de los medios, como sacramento y señal que ya anticipa y hace presente la salvación, pero que es llamada a desaparecer para dar lugar a los pueblos de Dios, en el reino definilivo (cfr. Ap 2I, 3).

Finalmente, en función de su misión en el mundo, hoy globalizado, la Iglesia se da a sí misma las estructuras y servicios que le parecen adecuados para cumplir su misión. Importa imitar el comportamiento de las comunidades eclesiales de los primeros liempos, que supieron Iraducir el mensaje de Jesús para un tiempo posterior, cuando ya no se esperaba la parusía, y asumieron formas de organización lomadas del medio circundanle, pero que les eran funcionales.

De acuerdo a la principales investigaciones, lanlo católicas como ecuménicas, se puede decir con seguridad que la Iglesia, en lo que concierne a su lado institucional, no puede ser deducida, directamente, del Nuevo Testamento. Este no conoce la estructura obispo-presbítero-diácono, presentada como un fetiche intocable por los documentos oficiales. Tal estructuración es testimoniada solamente a partir de san Ignacio de Antioquia, en la tercera generación apostólica. $\mathrm{Y}$, al decidir, las comunidades eclesiales originarias se inspiraban más en el Espíritu presente $(c f r$. Hch 15,28$)$ y en el Señor resucitado que en las referencias del pasado. Hoy, la Iglesia se confronta con la audacia de mirar hacia delante, pues frente a una situación absolutamente inédita, la emergencia de una única sociedad mundial, debe, en el espíritu, tomar decisiones, cargadas de consecuencias para el futuro del evangelio en el mundo. Como decía el viejo maestro Karl Rahner, la Iglesia debe ser atrevida, en la fuerza del resucitado y de su Espíritu, hasta el punto en que ir más allá scria herejía o traición. $Y$ se puede permitir tal audacia porque se siente divinamente acompañada. Sólo de esta forma se coloca a la altura de los desafíos mundiales. El desafío vale no sólo para esta o aquella Iglesia, sino para la totalidad del cristianismo como movimiento de Jesús, que debe articularse con otros movimientos espirituales, que también ofrecen su mensaje a la humanidad. Todos juntos son corresponsables para que lo Supremo que habita el ser humano no sea sofocado, ni erradicado de la faz de ia tierra: la presencia de Dios en el corazón del universo, en el centro mismo de la historia y en la profundidad del ser humano.

El ecumenismo no apunta solamente a la paz entre las iglesias y religiones por el muluo reconocimiento en el amor y en la cordialidad. sino, principalmente, a la paz entre las tribus del planeta y la paz perennc con la tierra misma, 
Magna Mater y Gaia. Sin esa paz, podremos sulrir el destino de los dinosaurios. El eje de la cuestión no es ya quién es Iglesia de Cristo y quién no lo es, sino cuál es el futuro del cristianismo, o de la civilización occidental, que sirvió de nicho encarnatorio a las principales iglesias. La nueva centralidad se encuentra en eso: esta vez no hay un arca de Noé que salve a algunos y deje perecer a los olros. O nos salvamos todos o nos perdemos todos, con o sin elementos eclesiales. ¿En qué medida la herencia de Jesús, la Iglesia católica con loda su pretensión de exclusividad, y las demás iglesias y comunidades cristianas ayudan a garantizar un futuro de vida y de esperanza para la tierra y la humanidad? Para eso debe servir el ecumenismo.

Ante la crisis de la tierra y de la humanidad, es diversionismo irresponsable hablar de subsistit in o de est, de "subsistencia" o de "ganar forma concreta". El Tiranic se está hundiendo para lodos, y algunos alienados, alegremente, lodavía insisten en ocuparse de tales cuestiones. Bien nos advirtió el Señor: "Cuando ven levantarse una nube en el poniente, enseguida dicen: vá a llover. Y así ocurre. Cuando sienten soplar el viento sur, dicen: va a hacer calor. $\mathrm{Y}$ así sucede... Hipócrilas, saben juzgar los fenómenos de la lierra y del cielo; enlonces, ¿cómo no saben juzgar el momento presente? ¿Por qué no juzgan por ustedes mismos lo que es justo?" (Lc 24, 54-57).

\section{Bibliografra mínima}

He aquí algunos títulos que presentan con más Jetalles la cuestión debatida en nuestro trabajo.

L. Boff, "Die katholische Kirche als Ganzsakrament und die sakramentale Struktur der nich-katholischen Kirchen", en Die Kirche als Sakrament im Horizont der Welterfahrung, Paderborn, 1972, pp 413-426.

L. Boff, Igreja: carisma e poder. Con lodos los Jocumentos de la polémica con el Vaticano y con mi respuesta inédita al Cardenal J. Ratzinger, Sāo Paulo, 1994.

G. Baum, "Die ekklesiale Wirklinchkeit der anderen Kirchen", Concilium 1 (1996) 291303.

Y. Congar, "Le développement de l'évaluation ecclésiolngique des Eglises non catholiques", Rev. Droit. Can. 25 (1975) 215-216.

W. Kasper, "Der ekklesiologische Charakter der nichtkatholischen Kirchen", ThQ 145 (1965) 42-62.

I. Ruidor, "Estructura sacramental de las iglesias y comunidades eristianas no católicas", Estudios Eclesidsticos 42 (1967) 207.216.

W. Dantine, "Die kontroverstheologische Problematik der sogenannten 'ekklesialen Elemente' im Blick aul das ökumenische Gespräch", en Erneuerung der einen Kirche (Festchr. Für H. Bornkamm, hrsg. von J Lell), Götlingen, 1966, pp. 140-155.

W. Dietzfelbinger, "Die Grenzen der Kirche nach der dogmatischen Konstitulion 'De Ecclesia"', Kerygma und Dogma 11 (1965) 165-176.

G. Thils, "Oecumenisme et romanocentrisme", Oecumenica 1967, pp. 194-207.

A. de Halleux, "Les principes catholiques de L'oecumenisme", Rev. Th. Louv. 16 (1985) 320-322.

A. Dulles, "The Church, the Churches and the Catholic Church", TS 33 (1972) 2 I Iss. 
P. W. Scheele, "Das Kirchenscin der Gelrennicn", Catholica 22 (1968) 30ss.

F. A. Sullivan, "In che scnso la Chicsa di Cristo 'sussislc' nclla Chicsa catlolica romana?" en Vaticano II: bilancio de prospettive a cura di René Latourelle, Vol. 2. Assisi, 1987, pp $811-824$.

Traducción de José María Vigil. 